\title{
Hiatal hernia as a rare cause of cardiac complications - case based review of the literature
}

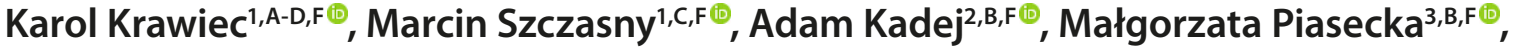 \\ Piotr Blaszczak ${ }^{1, C, F \oplus}$, Andrzej Głowniak ${ }^{4, A, C-F \oplus}$ \\ ${ }^{1}$ Department of Cardiology, Cardinal Wyszynski Hospital, Lublin, Poland \\ ${ }^{2}$ Department of General Surgery, Cardinal Wyszynski Hospital, Lublin, Poland \\ ${ }^{3}$ Department of Anaesthesiology and Intensive Therapy, Cardinal Wyszynski Hospital, Lublin, Poland \\ ${ }^{4}$ Department of Cardiology, Medical University, Lublin, Poland \\ A - Research concept and design, B - Collection and/or assembly of data, C - Data analysis and interpretation, \\ $D$ - Writing the article, E - Critical revision of the article, F - Final approval of article
}

\begin{abstract}
Krawiec K, Szczasny M, Kadej A, Piasecka M, Blaszczak P, Głowniak A. Hiatal hernia as a rare cause of cardiac complications - case-based
\end{abstract} review of the literature. Ann Agric Environ Med. 2021; 28(1): 20-26. doi: 10.26444/aaem/133583

\begin{abstract}
Introduction. Hiatal hernia $(\mathrm{HH})$ is a condition which refers to the protrusion of an intraabdominal organ in the thorax cavity throughan oesophageal hiatus of the diaphragm. Sliding $\mathrm{HH}$ is usually associated with non-specific symptoms, including heartburn, regurgitation or epigastric pain. Importantly, true paraesophageal hernia may lead to cardiac compression. Knowledge of cardiac manifestations of $\mathrm{HH}$ is limited.

Objective The main aim of the study is to present the rare case of a patient with gastrothorax due to hiatal hernia which caused cardiac arrest, and to provide a literature-based review of the cardiac aspects of hiatal hernia.

Brief description of the state of knowledge. Patients with paraesophageal hernia may experience arrhythmia, including sinus tachycardia, atrial flutter, atrial fibrillation, supraventricular extrasystole and ventricular tachycardia, as well as left bundle branch block, atrioventricular conduction block and electrocardiographic changes in the ST-segment and T-wave. In echocardiograph, $\mathrm{HH}$ may appear as an extracardiac posterior mass encroaching on the left atrial cavity, mimicking the left atrial mass. Rarel, $\mathrm{HH}$ may be manifested as tension gastrothorax leading cardiac arrest. In such a case, timely diagnosis and instant adequate treatment of the underlying condition are crucial.

Conclusions. Hiatal hernia should be considered as a possible cause of arrhythmia and changes in ST-T pattern, particularly if symptoms occurred after a meal. Differential diagnosis of the posterior mediastinal mass or intracardiac mass should include hiatal hernia. Gastrothorax is a rare condition associated with hiatal hernia which may lead to cardiac arrest. However, even timely recognition and therapy of gastrothorax does not ensure a positive clinical outcome.
\end{abstract}

Key words:

Gastrothorax, hiatus hernia, cardiac arrest, acute heart failure

\section{INTRODUCTION}

Hiatal hernia is a condition which refers to the protrusion of an intraabdominal organ or organs in the thorax cavity through an oesophageal hiatus of the diaphragm $[1,2,3]$. According to the classification based on the location of the gastroesophageal junction in relation to the crural pillar, there are four types of hiatal hernia $[1,4]$. Type I is also known as a sliding hernia and is defined as a displacement of the gastroesophageal junction above the diaphragm. This is the most common type of hiatal hernia which accounts for approximately 85-95\% of all hiatal hernias. Types II, III and IV are classified as true paraesophageal hernias and represent about $5-15 \%$ of cases of hiatal hernia. Type II is characterized by the herniation of the gastric fundus. Type III is the most common type of true paraesophageal hernias, and results from the herniation of gastric fundus and gastroesophageal junction through the diaphragmatic hiatus. The hernia may enlarge, drawing other parts of stomach into the chest [4]. Type IV results from a

Address for correspondence: Andrzej Głowniak, Department of Cardiology, Medical University of Lublin, ul. Jaczewskiego 8, 20-090, Lublin, Poland

E-mail: andrzej.glowniak@gmail.com

Received: 27.01.2021; accepted: 22.02.2021; first published: 08.03.2021 large defect in the phrenoesophageal membrane leading to the herniation of stomach and other abdominal organs [1-4]. Figure 1 presents classification of hiatal hernia.

There is no single definition of a massive hiatal hernia. It may be defined as a hernia which is bigger than $5 \mathrm{~cm}$, or to the herniation of the entire stomach into the mediastinum [5]. Giant hiatal hernia may also refer to a herniation of more than $30 \%$ or - by other authors -more than $50 \%$ of the stomach [6]. Some authors indicate that the size of hernia is not sufficient to be the sole criterion of massive hernia [5]. Thus, there are reports of a massive hiatal hernia which encompasses type II, III and IV [5].

While sliding hernia is usually associated with the gastroesophageal reflux disease, paraesophageal hernias may lead to the obstruction, ischemia, or volvulus of the contents of the hernial sac [3]. It may also cause respiratory distress due to compression of the lung [5]. Large hiatal hernia may also result in the displacement and compression of the heart [7]. However, data about cardiac manifestations of hiatal hernia are scarce and mostly limited to case reports. The aim of this study is to present the case of a patient with a giant hiatal hernia which caused cardiac arrest, and to present a review of the literature of the cardiological aspects of hiatal hernia. 


\section{TYPES OF HIATAL HERNIA}
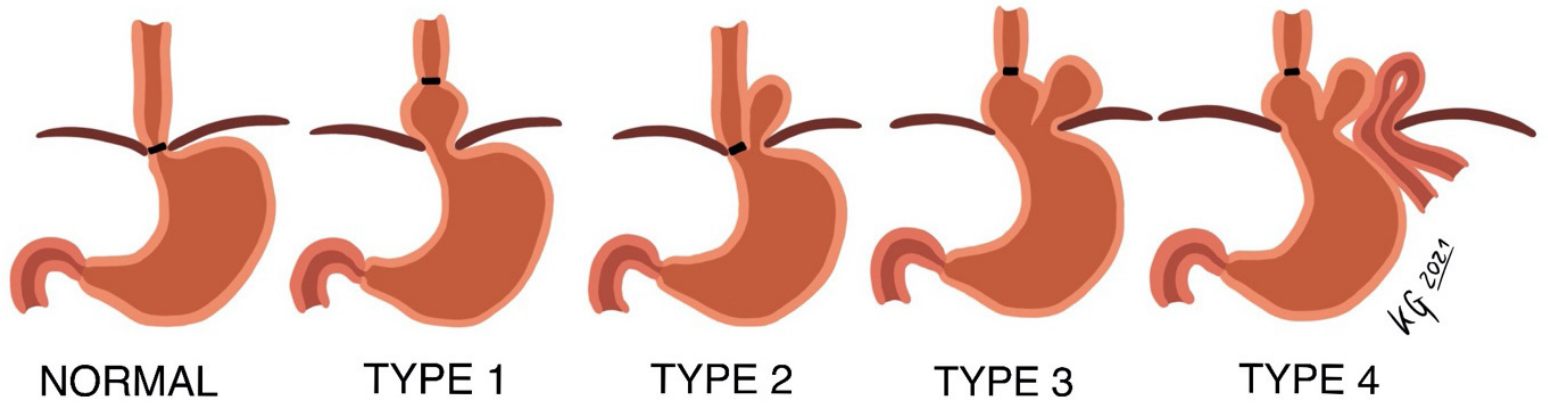

Figure 1. Types of hiatal hernia

\section{CASE STUDY}

A 51-year-old, obese (BMI $\left.30.86 \mathrm{~kg} / \mathrm{m}^{2}\right)$ agricultural worker was admitted to the Emergency Department due to severe epigastric pain and vomiting, following the lifting of heavy fertilizer bags.

In physical examination on admission the patient was tachycardiac (150/min) with tachypneic (30/min). Blood pressure was normal $110 / 60 \mathrm{mmHg}$ although the pulse was hypokinetic and jugular vein distention was present. Chest examination revealed a dull percussion note and absence of respiratory sounds in the left haemithorax. The abdomen was distended, with tenderness in the epigastric area.

Electrocardiogram (ECG) displayed sinus tachycardia, intermediate heart axis, low voltage of QRS complexes, incomplete right bundle branch block, q in leads II, III and aVF.

Computed tomography (CT) of chest and abdomen performed without delay revealed a giant hiatal hernia strangulated in the chest cavity, with hernia's gate about $7 \mathrm{~cm}$. The stomach was distended, twisted and significantly (>50\%) translocated into the chest resulting in displacement and compression of the heart. The hiatal sac included also a part of the duodenum and its mesentery. The portal venous gas was stated and the left lung significantly compressed (Fig. 2).

The patient was referred for an emergency thoracotomy and laparotomy. Directly after transportation of the patient to the operating theatre, sudden cardiac arrest in the mechanism of pulseless electrical activity (PEA) occurred. Immediate left-sided thoracotomy was performed to release the trapped viscera, and to enable direct cardiac massage which was successfully performed and normal sinus rhythm restored. Afterwards, during laparotomy, hernia content was returned to the abdominal cavity, the hiatus hernia repaired and the patient transferred to the intensive care unit. Regardless of the effective surgical intervention, in the postoperative period the patients experienced significant complications, including cardiac and respiratory failure, post-cardiac arrest brain injury, acute kidney injury and gastrointestinal bleeding. $\mathrm{He}$ required mechanical ventilation and continuous infusion of catecholamines, haemodialysis, neuroprotective treatment, and broad-spectrum antibiotics. The patient died on day 22 after surgery due to multiple-organ failure.

\section{DISCUSSION}

Tension gastrothorax as hiatal hernia complication. Tension gastrothorax is a rare and life-threating condition, which causes contralateral shift and compression of the mediastinal structures by translocation of the stomach into the chest cavity $[8,9]$. It is usually associated with congenital diaphragmatic hernia in children, or occurs due to diaphragmatic injury as a result of trauma or complication

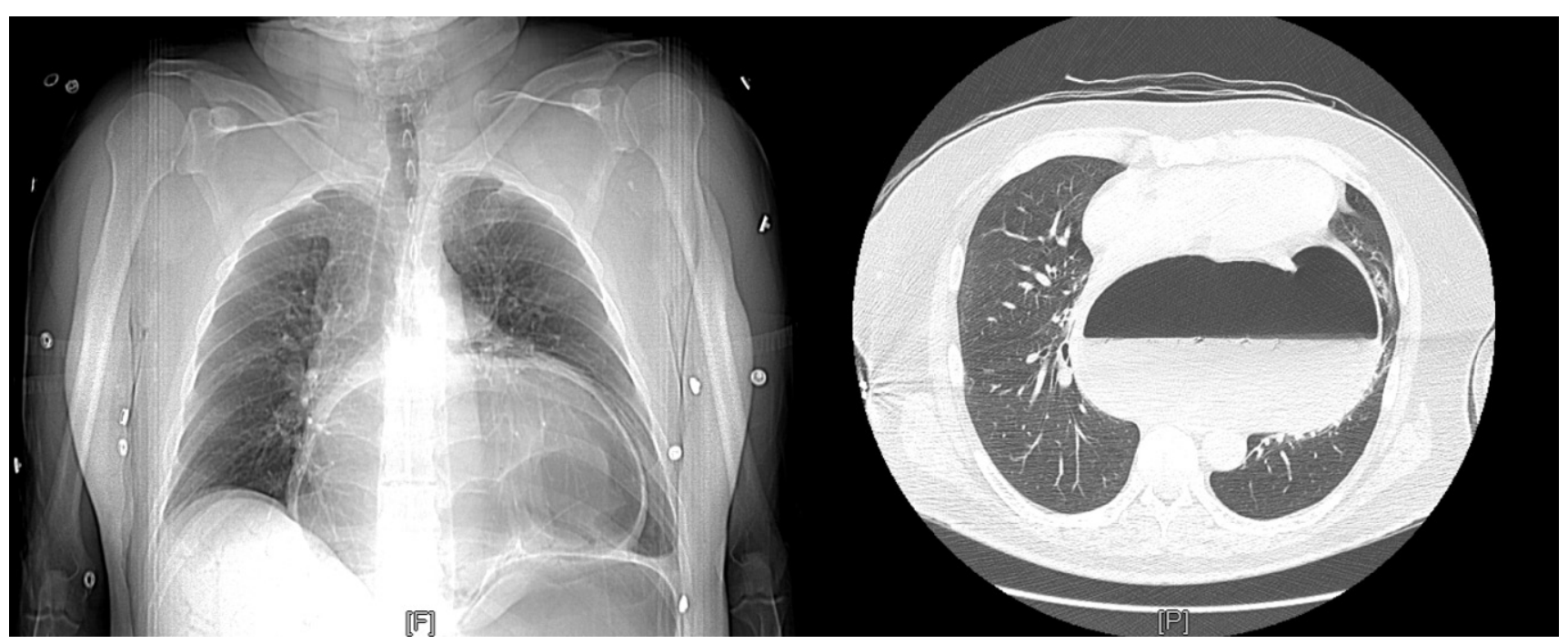

Figure 2. Chest CT scans showing giant hiatal hernia causing massive compression of the heart 
of some surgical procedures [10, 11]. Sporadically, tension gastrothorax may be a manifestation of hiatal hernia - as in case of the presented patient $[8,10]$. Tension gastrothorax may be difficult to diagnose because its clinical manifestations, including dyspnea, tachycardia and hypotension, may mimic pneumothorax $[9,10]$. However, contrary to the pneumothorax, in the gastrothora, bowel sounds may be auscultated over the lungs fields [9]. Patients with gastrothorax may also present with abdominal pain and vomiting [9]. Tension gastrothorax may lead to cardiopulmonary arrest $[9,10]$ which ensues due to extrinsic compression of the heart by the strangulated hiatal herni, which occurred in the presented case.

There are only few published case reports of tension gastrothorax complicated by cardiac arrest [8-15]. The majority were caused by trauma $[9,11-14]$, while by hiatal hernia in only two cases by $[8,10]$. Solé et al. reported thecase of a 75 -year-old man with chest pain, dyspnea and nausea. Minor increase of troponin I with ST-segment depression in ECG suggested acute coronary syndrome. The patient experienced cardiopulmonary arrest, recovering after resuscitation, but with persistent hypotension. Echocardiogram did not show any significant abnormalities. Chest CT revealed a giant hiatal hernia causing cardiac displacement, and compression of the left lobar bronchus [8]. Shoij et al. presented the case of a 60 -year-old man with suspected myocardial infarction as an underlying condition of cardiopulmonary arrest. However, in echocardiogram there were no abnormalities, and further imaging studies revealed tension gastrothorax due to a hiatal hernia as the actual cause of cardiac arrest [10]. Thus, it appears that tension gastrothorax may mimic acute coronary syndrome and should be considered as a potential reason of cardiac arrest.

Diagnosis of tension gastrothorax should be based on clinical signs and symptoms, although timely imaging studies are essential for the appropriate diagnosis. Radiological signs suggesting gastrothorax include the presence of abdominal organs in the thorax, elevated diaphragm, compressive atelectasis, mediastinal displacement, visible fluid levels, and/or the presence of gas bubbles in the chest $[12,16]$. In the current case, a CT scan of the abdomen and chest revealed the presence of massive hiatal hernia which compressed the heart to the anterior thoracic wall, and constricted the left lung.

The emergency initial management of gastrothorax included decompression of the stomach by the placement of a nasogastric or orogastric tube [10]; laparotomy or thoracotomy was the treatment of choice. In the presented case, the patient required both. Similar management was needed in a patient reported by Shoji et al. [10]. However, according to the literature, some patients with gastrothorax complicated by cardiac arrest underwent solely laparotomy $[13,14]$ or thoracotomy $[9,11]$. During the surgery, the anatomical position of the organs is restored and the hiatus hernia repaired [10]. It should be highlighted that laparoscopy can increase the pressure in the abdominal cavity, thus it should be performed with caution [10].

Hiatal hernia and changes in electrocardiogram. Changes in the electrocardiogram pattern and rhythm have been observed in patients with hiatal hernias [17-35]. However, the linkage between these conditions has not been fully elucidated. Table 1 presents a summary of selected case reports of patients with abnormal findings in electrocardiogram, presumably triggered by the hiatal hernia reported in the literature.

In most cases, electrocardiographic alternation disappeared after initial stomach decompression or surgical correction of the hiatal hernia [18, 20, 21, 30-35], or after successful conservative management with dietary control and proton pump inhibitor [29]. Resolution of abnormal findings in ECG after management of hiatal hernia may imply a causal relationship between the hiatal hernia and changes in the electrocardiogram pattern and rhythm. However, ECG repolarization disorders persistent up to three months have been observed after successful surgery, possibly due to pericardial irritation [26]. Roy et al. carried out a retrospective analysis of patients with hiatal hernia for the presence of atrial fibrillation. The authors demonstrated that $7.1 \%$ of all patients with hiatal hernia experienced atrial fibrillation. Interestingly, the prevalence of atrial fibrillation was 17.5-fold and 19-fold higher in men and women younger than 55 years with hiatal hernia, compared to the general population [36].

Although the exact mechanism of changes in electrocardiogram related to the hiatal hernia is not well understood, some hypotheses have attempted to explain these findings. Schilling et al. suggested that persistent compression of the left atrium by the hiatal hernia may result in an area of relative ischemia and conduction block, causing reentry [31]. Another explanation of changes in electrocardiogram may be the stimulation of the vagal nerve by pressure from the hiatal hernia [31, 37]. Increased vagal tone may precipitate the onset of tachycardia in the mechanism similar to that in bradycardia-tachycardia syndrome [29]. Kounis et al. presumed that the increase in direct or indirect pressure exerted on the global surface of the heart appears to be the cause of the electrical alternation observed in electrocardiography of patients with increased intrathoracic pressure, including those with hiatal hernia [38]. Maruyama et al. implied that mechanical contact and irritation on the left atrium or pulmonary veins by the hiatal hernia may contribute to the ectopic firing leading to the atrial fibrillation [39]. Roy et al. suggested that since hiatal hernia is related to reflux oesophagitis, the inflammation may extend to the surrounding organs, including the left atrium, and lead to tachyarrhythmia due to mechanical or chemical/neural impact mediated through the vagal or sympathetic nervous system [36]. Basir et al. hypothesized that ST elevation may be related to torsion or compression of the epicardial artery from direct pressure from the hiatal hernia [21]. In patients without hiatal hernia but with extreme abdominal distension and hemi-diaphragm elevation, it has been also suggested that elevation of ST in the electrocardiograph may result from the mechanical compression or transient vasospasm of one or more coronary arteries from the diaphragm impinging on the myocardium from severe abdominal distention [40].

Patients with a large hiatal hernia may experience arrhythmias, including sinus tachycardia, atrial flutter, atrial fibrillation, supraventricular extrasystole and ventricular tachycardia, as well as left bundle branch block, atrioventricular conduction block and electrocardiographic changes in the ST-segment and T-wave. There is a need to consider hiatal hernia as a reason for the abnormal electrocardiogram pattern and rhythm, particularly in patients with clinical symptoms that occurred after meals or in the supine position. 
Table 1. Selected case reports of patients with hiatal hernia and abnormal findings in ECG

\begin{tabular}{|c|c|c|c|c|c|c|c|c|}
\hline Case & Gender & Age & Symptoms & ECG & $\mathrm{ECHO}$ & X-ray & $\mathrm{CT}$ & Surgical method \\
\hline $\begin{array}{l}\text { Schumer W. } \\
2017 \text { [17] }\end{array}$ & M & 73 & $\begin{array}{l}\text { Dyspnea, } \\
\text { chest pain }\end{array}$ & $\begin{array}{l}\text { Left bundle branch } \\
\text { block }\end{array}$ & No information & $\begin{array}{c}\text { Cardiomegaly, large mass } \\
\text { behind the heart }\end{array}$ & Large $\mathrm{HH}$ & Not described \\
\hline $\begin{array}{l}\text { Hokamaki J. } \\
\text { et al. } 2005 \text { [18] }\end{array}$ & $\mathrm{F}$ & 79 & $\begin{array}{l}\text { Chest pain, } \\
\text { vomiting }\end{array}$ & ST-T changes & $\begin{array}{l}\text { Mass compressing } \\
\text { LA, LV, IVC }\end{array}$ & $\begin{array}{l}\text { Large shadow overlapping } \\
\text { cardiac silhouette }\end{array}$ & $\begin{array}{l}\text { Type III giant } \mathrm{HH} \\
\text { compressing the } \\
\text { heart and IVC }\end{array}$ & $\begin{array}{c}\text { Nissen fundoplication, } \\
\text { Hill's method }\end{array}$ \\
\hline $\begin{array}{l}\text { Zanini G. et al. } \\
2009 \text { [19] }\end{array}$ & $\mathrm{F}$ & 78 & Dyspnea & ST-T changes & Mass in LA & Normal & No information & $\begin{array}{c}\text { Non-operative } \\
\text { treatment }\end{array}$ \\
\hline $\begin{array}{l}\text { Gard J.J. et al. } \\
2011[20]\end{array}$ & M & 73 & $\begin{array}{l}\text { Abdominal } \\
\text { pain }\end{array}$ & ST-T changes & $\begin{array}{l}\text { LV distortion with } \\
\text { asynchronous } \\
\text { contraction }\end{array}$ & Large $\mathrm{HH}$ & $\begin{array}{l}\text { Large } \mathrm{HH} \text {, gastric } \\
\text { volvulus }\end{array}$ & Nissen fundoplication \\
\hline $\begin{array}{l}\text { Basir B. et al. } \\
2013 \text { [21] }\end{array}$ & M & 86 & Nausea & ST-T changes & Normal & Large $\mathrm{HH}$ & $\begin{array}{l}\text { Large } \mathrm{HH} \text {, gastric } \\
\text { volvulus }\end{array}$ & Nissen fundoplication \\
\hline $\begin{array}{l}\text { Narala K. et al. } \\
2014[22]\end{array}$ & M & 72 & $\begin{array}{l}\text { Abdominal } \\
\text { pain, } \\
\text { presyncopal } \\
\text { episodes }\end{array}$ & ST-T changes & $\begin{array}{l}\text { Mass compressing } \\
\text { LV, dyskinesis } \\
\text { of inferior and } \\
\text { lateral LV }\end{array}$ & $\begin{array}{l}\text { Left lung compression with } \\
\text { a radiopaque left lung field }\end{array}$ & Large $\mathrm{HH}$ & Gastropexy \\
\hline $\begin{array}{l}\text { Rossington J.A. } \\
\text { et al. } 2014 \text { [23] }\end{array}$ & $\mathrm{F}$ & 66 & $\begin{array}{l}\text { Abdominal } \\
\text { pain, } \\
\text { vomiting }\end{array}$ & ST-T changes & Collapse of LA & No information & $\begin{array}{l}\text { Perforated volvulus } \\
\text { of the stomach; } \mathrm{HH}\end{array}$ & Laparoscopy \\
\hline $\begin{array}{l}\text { Kakarala K. } \\
\text { et al. } 2015 \text { [24] }\end{array}$ & M & 41 & $\begin{array}{l}\text { Chest pain, } \\
\text { dyspnea }\end{array}$ & ST-T changes & No information & $\begin{array}{l}\mathrm{HH} \text {, pneumopericardium, } \\
\text { pleural thickening or fluid } \\
\text { in the left base }\end{array}$ & $\begin{array}{c}\text { Type I HH, } \\
\text { pneumopericardium, } \\
\text { pericardial effusion }\end{array}$ & $\begin{array}{l}\text { Thoracotomy, } \\
\text { laparotomy }\end{array}$ \\
\hline $\begin{array}{l}\text { Harada K. et al. } \\
2017[25]\end{array}$ & M & 76 & Chest pain & ST-T changes & $\begin{array}{l}\text { Mass compressing } \\
\text { LA and LV }\end{array}$ & $\begin{array}{c}\text { Gastric bubble and air-fluid } \\
\text { level overlapping cardiac } \\
\text { silhouette }\end{array}$ & $\begin{array}{l}\text { Large } \mathrm{HH} \\
\text { compressing LA } \\
\text { and LV }\end{array}$ & Not described \\
\hline $\begin{array}{l}\text { Rubini- } \\
\text { Gimenez M. } \\
\text { et al. } 2019 \text { [26] }\end{array}$ & $\mathrm{F}$ & 61 & $\begin{array}{l}\text { Dyspnea, } \\
\text { chest pain }\end{array}$ & ST-T changes & $\begin{array}{c}\text { Diastolic } \\
\text { dysfunction, high } \\
\text { PAP }\end{array}$ & No information & Giant HH & Laparoscopy \\
\hline $\begin{array}{l}\text { Arvind A. et al. } \\
2019 \text { [27] }\end{array}$ & $\mathrm{F}$ & 87 & $\begin{array}{l}\text { Chest pain, } \\
\text { nausea }\end{array}$ & ST-T changes & $\begin{array}{l}\text { Mass compressing } \\
\text { LA and LV causing } \\
\text { tamponade } \\
\text { physiology }\end{array}$ & No information & $\begin{array}{c}\text { Large } \mathrm{HH} \\
\text { compressing the } \\
\text { heart }\end{array}$ & Toupet fundoplication \\
\hline
\end{tabular}

\begin{tabular}{|c|c|c|c|c|c|c|c|c|}
\hline $\begin{array}{l}\text { Gürgün C. et al. } \\
2002[28]\end{array}$ & $\mathrm{F}$ & 76 & Dyspnea & Atrial fibrillation & Normal & $\begin{array}{c}\text { Cardiomegaly, a } \\
\text { dome shaped air level } \\
\text { overlapping cardiac } \\
\text { silhouette }\end{array}$ & No information & Laparoscopy \\
\hline $\begin{array}{l}\text { Duygu H. et al. } \\
2008[29]\end{array}$ & $\mathrm{F}$ & 79 & Chest pain & Atrial fibrillation & TR, MR, high PAP & No information & $\mathrm{HH}$ & $\begin{array}{c}\text { Non-operative } \\
\text { treatment }\end{array}$ \\
\hline $\begin{array}{l}\text { Cristian D.A. } \\
\text { et al. } 2015 \text { [30] }\end{array}$ & $\mathrm{F}$ & 77 & Dyspnea & Atrial fibrillation & $\begin{array}{c}\text { Mass compressing } \\
\text { LA, MR }\end{array}$ & $\begin{array}{c}\text { Widening of the } \\
\text { mediastinum, large } \\
\text { shadow overlapping the } \\
\text { heart }\end{array}$ & No information & Nissen fundoplication \\
\hline $\begin{array}{l}\text { Schilling R.J. } \\
\text { et al. } 1998 \text { [31] }\end{array}$ & M & 72 & $\begin{array}{c}\text { Hearth } \\
\text { palpitations }\end{array}$ & $\begin{array}{l}\text { Atrial flutter with 2:1 } \\
\text { AV block }\end{array}$ & Normal & Large mediastinal mass & No information & Not described \\
\hline $\begin{array}{l}\text { Patel A. et al } \\
2014 \text { [32] }\end{array}$ & $\mathrm{F}$ & 80 & $\begin{array}{l}\text { Failure to } \\
\text { thrive and } \\
\text { weakness }\end{array}$ & Atrial flutter & High PAP & $\begin{array}{l}\text { Cardiomegaly, a large } \\
\text { lucency involving the mid } \\
\text { and lower hemi-thoraces }\end{array}$ & Large $\mathrm{HH}$ & Gastropexy \\
\hline $\begin{array}{l}\text { Tursi A. et al. } \\
2001 \text { [33] }\end{array}$ & $\mathrm{F}$ & 75 & $\begin{array}{l}\text { Weakness, } \\
\text { dysphagia, } \\
\text { heartburn }\end{array}$ & $\begin{array}{l}\text { Supraventricular } \\
\text { extrasystole, atypical } \\
\text { right bundle branch } \\
\text { block pattern, and } \\
\text { inferior axis }\end{array}$ & No information & $\begin{array}{l}\text { Giant gastric } \mathrm{HH} \\
\text { compressing LA }\end{array}$ & No information & $\begin{array}{l}\text { Nissen-Rossetti } \\
\text { fundoplication }\end{array}$ \\
\hline $\begin{array}{l}\text { Gnanenthiran } \\
\text { S.R. et al. [34] }\end{array}$ & M & 78 & Syncope & $\begin{array}{l}\text { Ventricular } \\
\text { tachycardia }\end{array}$ & $\begin{array}{l}\text { Mass compressing } \\
\text { LA, dyskinesis } \\
\text { of LV }\end{array}$ & No information & No information & Laparoscopy \\
\hline $\begin{array}{l}\text { Gleadle J. et al. } \\
1989 \text { [35] }\end{array}$ & $\mathrm{F}$ & 65 & Vomiting & $\begin{array}{l}\text { Sinus tachycardia, } \\
\text { ST-T changes }\end{array}$ & $\begin{array}{l}\text { HH compressing } \\
\text { and displacing the } \\
\text { heart }\end{array}$ & Very large $\mathrm{HH}$ & No information & Not described \\
\hline Present report & $M$ & 51 & $\begin{array}{l}\text { Abdominal } \\
\text { pain }\end{array}$ & $\begin{array}{c}\text { Sinus tachycardia, } \\
\text { low voltage of } \\
\text { QRS complexes, } \\
\text { incomplete right } \\
\text { bundle branch block }\end{array}$ & No information & No information & $\begin{array}{c}\text { Giant HH } \\
\text { compressing and } \\
\text { displacing the heart }\end{array}$ & $\begin{array}{c}\text { Thoracotomy, } \\
\text { laparotomy }\end{array}$ \\
\hline
\end{tabular}

F - female; HH - hiatal hernia; IVC - inferior vena cava; LA - left atrium; LV - left ventricle; M - male; MR - Mitral regurgitation; PAP - pulmonary arterial pressure; TR -Tricuspid regurgitation 
Hiatal hernia and echocardiography. Hiatal hernia may be visualized in the transthoracic echocardiogram while it is encroaching on the posterior part of the left atrium and left atrioventricular junction [41]. Hiatal hernia is usually seen as an extracardiac posterior mass encroaching on the left atrial cavity, mimicking a left atrial mass on transthoracic echocardiography $[25,42-54]$. However, this may not be obviously apparent since its visualization relates to the imaging plane and respiratory fluctuation [41]. It has been observed that hiatal hernia is seen in its maximal dimension while the left atrium is imaged in a posterior plane. On the other hand, while the eft atrium is imaged in an anterior plane, the hiatal hernia appears to be progressively smaller or even absent on transthoracic echocardiography [55].

D'Cruz et al. described features of hiatal hernia commonly seen on the echocardiograp, including:

- a large ill-defined amorphous solid mass apparently filling all or most of the left atrial chamber in the apical 4-chamber view (imaging the posterior atrial plane), which sometimes may extends across the atrial septum into the adjacent right atrial space;

- a large convex poorly-demarcated mass impinging on the posterior left atrial wall, atrioventricular junction, or even occasionally on the postero-basal left ventricular wall in the parasternal or apical long-axis views;

- paradoxical motion of the left ventricular wall if there is its encroachment;

- respiratory fluctuation in degree of encroachment of the hiatal hernia mass on the left atrium;

- normal sonolucency of the descending thoracic aorta in the apical 4-chamber and long-axis views partly or completely obscured by the large echogenic hiatal hernia [55].

Oral ingestion of a carbonated beverage may lead to visualization of swirling echodensities in the mass or distinct echo-free space replacing a substantial portion of the original 'mass', facilitating the differential diagnosis between a true left atrial mass and a hiatal hernia on transthoracic echocardiogram $[42,50,55,56]$. The use of intravenous echocardiographic contrast may also be helpful in establishing the diagnosis of hiatal hernia [56]. Smelly et al. suggested that the combination of an oral ingestion of carbonated beverage mixed with echocardiographic contrast media should better delineate extracardiac structures [56].

Hiatal hernia may be difficult to visualize in the transesophageal echocardiography because of the inability to obtain adequate images [57]. However, Frans et al. suggested that on the transesophageal echocardiography, hiatal hernia may be seen as a posterior, mass-like lesion with microbubbles, and thick inner lining resembling the stomach mucosa [58].

There have been several papers reporting left atrial compression with haemodynamic collapse and heart failure due to hiatal hernia [59-62]. However, only Ishibashi et al. have presented a hiatal hernia which protruded into the left ventricle and caused paradoxical movement in the posterior wall [60].

Hiatal hernia should be taken into consideration if a posterior mediastinal mass impinging on the left atrium is visualized in the echocardiogram [56]. However, differentiation of hiatal hernia with other posterior mediastinal mass lesions or intracardiac masses may be challenging for echocardiographists. Thus, it requires additional imaging, including computed tomography or magnetic resonance imaging [63].

Hiatal hernia mimicking cardiac tamponade. Hiatal hernia has been reported as a rare cause of cardiac compression mimicking cardiac tamponade due to a distended stomach after coronary artery bypass and post-type A aortic dissection repair surgery [64-66]. It has been suggested that patients with hiatal hernia may benefit from a prophylactic nasogastric tube placement prior cardiac surgery, limiting the risk of gastric stasis, vomiting, aspiration pneumonia and haemodynamic compromise [64, 65]. Prompt decompression of the dilated stomach results in the improvement of the haemodynamic status of patient and resolution of the symptoms $[65,66]$.

Extra-pericardial pathologies including hiatal hernia should be considered in patients' post-cardiac surgeries with symptoms suggesting cardiac tamponade without its objective evidence on echocardiography $[64,65]$.

Hiatal hernia and syncope. In the literature there are several reports of a syncope due to a huge hiatal hernia. Saito et al. reviewed nine cases of syncope related to hiatal hernia from the literature between January 1995 - August 2016 [67]. Most of the reported episodes of syncope occurred after eating an unusually large meal. It has been suggested that compression of the enlarged stomach on the left atrium may be the cause of syncope [68]. Haemodynamic instability due to the cardiac compression may result in a decreased preload and cardiac output which lead to syncope [69]. Differential diagnosis of left atrium compression should also include tumours and thrombosis; therefore, further imaging studies may be necessary for final recognition [70]. Maekawa et al. reproduced a syncopal attack in their patient using a water pouring test through a nasogastric tube [71]. Hiatal hernia should therefore be considered in the differential diagnosis of postprandial syncope.

\section{CONCLUSIONS}

In conclusion, hiatal hernia should be considered as a reason of arrhythmia and changes in the ST-T pattern, particularly if clinical symptoms occurred after a meal. Differential diagnosis of posterior mediastinal mass lesions or intracardiac masses should include hiatal hernia. Gastrothorax is a rare condition associated with hiatal hernia which may lead to cardiac arrest. Early diagnosis based on imaging studies enables appropriate management. However, even timely recognition and therapy of gastrothorax does not ensure a positive clinical outcome.

\section{REFERENCES}

1. Sfara A, Dumitrascu DL. The management of hiatal hernia: an update on diagnosis and treatment. Med Pharm Rep. 2019; 92(4): 321-325. doi: $10.15386 / \mathrm{mpr}-1323$

2. Rochefort M, Wee, JO. Management of the Difficult Hiatal Hernia. Thorac Surg Clin. 2018; 28(4): 533-539. doi: 10.1016/j.thorsurg.2018.07.001

3. Roman S, Kahrilas PJ. The diagnosis and management of hiatus hernia. BM. 2014; 349. doi: 10.1136/bmj.g6154

4. Siegal SR, Dolan JP, Hunter JG. Modern diagnosis and treatment of hiatal hernias. Langenbecks Arch Surg. 2017; 402(8): 1145-1151. doi: 10.1007/s00423-017-1606-5 
Karol Krawiec, Marcin Szczasny, Adam Kadej, Małgorzata Piasecka, Piotr Blaszczak, Andrzej Głowniak. Hiatal hernia as a rare cause of cardiac complications..

5. Duranceau A. Massive hiatal hernia: a review. Dis Esophagus. 2016; 29(4): 350-366. doi: 10.1111/dote.12328

6. Mitiek MO, Andrade RS. Giant hiatal hernia. Ann Thorac Surg. 2010; 89(6): 2168-2173. doi: 10.1016/j.athoracsur.2010.03.022

7. Naoum C, Falk GL, Ng AC, et al. Left atrial compression and the mechanism of exercise impairment in patients with a large hiata hernia. J Am Coll Cardiol. 2011; 58(15): 1624-1634. doi: 10.1016/j. jacc.2011.07.013

8. Solé, C, Rojas S, Vives JP, Sanz E. Tension gastrothorax mimicking acute coronary syndrome and causing cardiac arrest. Eur Heart J. 2014; 35(12): 794. doi: 10.1093/eurheartj/eht336

9. Tokur M, Demiröz \$̦M, Sayan M. Non-traumatic tension gastrothorax in a young lady. Ulus Travma Acil Cerrahi Derg. 2015; 21(4): 306-308. doi: $10.5505 /$ tjtes. 2015.71245

10. Shoji T, Tarui T, Kaita Y, et al. A survival case of tension gastrothorax due to hiatal hernia, the key of life-saving is thoracotomy. Am J Emerg Med. 2017; 35(1): 199.e3-199.e5. doi: 10.1016/j.ajem.2016.07.043

11. Kao Y, Lee WJ, Lin HJ. Tension gastrothorax: a life-threatening cause of acute abdominal pain. CMAJ 2009; 180(9): 983. doi: 10.1503/cmaj.081094

12. Ingelbrecht SN, Kint PA, Belderbos HN. Gastrothorax mimicking acute tension pneumothorax. Acta Clin Belg. 2007; 62(3): 184-186. doi: $10.1179 / \mathrm{acb} .2007 .030$

13. Rathinam S, Margabanthu G, Jothivel G, et al. Tension gastrothorax causing cardiac arrest in a child. Interact Cardiovasc Thorac Surg. 2002; 1(2): 99-101. doi:10.1016/s1569-9293(02)00064-6

14. Ahn S, Kim W, Sohn CH, et al. Tension viscerothorax after blunt abdominal trauma: a case report and review of the literature. J Emerg Med. 2012; 43(6): 451-453. doi: 10.1016/j.jemermed.2011.05.084

15. Flamée P, Pregardien C. Tension gastrothorax causing cardiac arrest. CMAJ 2012; 184(1): 82. doi: 10.1503/cmaj.110715

16. McCann B, O'Gara A. Tension viscerothorax: an important differential for tension pneumothorax. Emerg Med J. 2005; 22(3): 220-221. doi: 10.1136/emj.2003.008367

17. Schummer W. Hiatal hernia mimicking heart problems. BMJ Case Rep. 2017. doi:10.1136/bcr-2017-220508

18. HokamakiJ, KawanoH, MiyamotoS, etal. Dynamic electrocardiographic changes due to cardiac compression by a giant hiatal hernia. Intern Med. 2005; 44(2): 136-140. doi: 10.2169/internalmedicine.44.136

19. Zanini G, Seresini G, Racheli M, et al. Electrocardiographic changes in hiatal hernia: a case report. Cases J. 2009; 2: 8278. doi: 10.4076/17571626-2-8278

20. Gard JJ, Bader W, Enriquez-Sarano M, et al. Uncommon cause of ST elevation. Circulation 2011; 123(9); 259-261. doi: 10.1161/ CIRCULATIONAHA.110.002477

21. Basir B, Safadi B, Kovacs RJ, at al. A Rare Case of Transient Inferior ST Segment Elevation. Heart Views 2013; 14(3): 117-120. doi: 10.4103/1995 $705 X .125928$

22. Narala K, Banga S, Hsu M, et al. Hiatal hernia mimicking ST elevation myocardial infarction. Cardiology 2014; 129(4): 258-261. doi: $10.1159 / 000367778$

23. Rossington JA, Balerdi M, Hoye AJ. Noncardiac pathology exposed at coronary angiography for ST-segment elevation. JACC Cardiovasc Interv. 2014; 7(5): 41-43. doi: 10.1016/j.jcin.2013.07.025

24. Kakarala K, Edriss H, Nugent K. Gastropericardial fistula as a delayed complication of a Nissen fundoplication. Proc (Bayl Univ Med Cent) 2015; 28(4): 478-481. doi: 10.1080/08998280.2015.11929314

25. Harada K, Tamura U, Ichimiya C, et al. Left ventricular obstruction caused by a large hiatal hernia. Echocardiography 2017; 34(8): 1254 1256. doi: 10.1111 /echo.13563

26. Rubini Gimenez M, Gonzalez Jurka L, Zellweger MJ, et al. A case report of a giant hiatal hernia mimicking an ST-elevation myocardial infarction. Eur Heart J Case Rep. 2019; 3(3): 138. doi: 10.1093/ehjcr/ ytz138

27. Arvind A, Niec R, Hajifathalian K, et al. Hiatal Hernia Presenting with Recurrent Non-ST Elevation Myocardial Infarction and Cardiac Tamponade. ACG Case Rep J. 2019; 6(12): e00278. doi: 10.14309/ crj.0000000000000278

28. Gürgün C, Yavuzgil O, Akín M. Images in cardiology. Paraoesophageal hiatal hernia as a rare cause of dyspnoea. Heart. 2002; 87(3): 275. doi:10.1136/heart.87.3.275

29. Duygu H, Ozerkan F, Saygi S, et al. Persistent atrial fibrillation associated with gastroesophageal reflux accompanied by hiatal hernia. Anadolu Kardiyol Derg. 2008; 8(2): 164-165.

30. Cristian DA, Constantin AS, Barbu M, et al. Paroxysmal postprandial atrial fibrilation suppressed by laparoscopic repair of a giant paraesophageal hernia compressing the left atrium. J Gastrointestin Liver Dis. 2015; 24(1): 113-116. doi: 10.15403/jgld.2014.1121.dac
31. Schilling RJ, Kaye GC. Paroxysmal atrial flutter suppressed by repair of a large paraesophageal hernia. Pacing Clin Electrophysiol. 1998;21(6): 1303-1305. doi: 10.1111/j.1540-8159.1998.tb00191.x

32. Patel A, Shah R, Nadavaram S, et al. Hiatal hernia squeezing the heart to flutter. Am J Emerg Med. 2014; 32(4): 392. doi: 10.1016/j. ajem.2013.10.024

33. Tursi A, Cuoco L. Recurrent supraventricular extrasystolia due to retrocardiac stomach. Am J Gastroenterol. 2001; 96(1): 257-258. doi:10.1111/j.1572-0241.2001.03494.x

34. Gnanenthiran SR, Naoum C, Kilborn MJ, et al. Posterior cardiac compression from a large hiatal hernia - A novel cause of ventricular tachycardia. HeartRhythm Case Rep. 2018; 4(8):362-366. doi:10.1016/j. hrcr.2018.05.003

35. Gleadle J, Dennis M. A thrilling case of hiatus hernia. Postgrad Med J. 1989; 65(769): 832-834. doi: 10.1136/pgmj.65.769.832

36. Roy RR, Sagar S, Bunch TJ, et al. Hiatal Hernia Is Associated With an Increased Prevalence of Atrial Fibrillation in Young Patients. J Atr Fibrillation. 2013; 6(2): 894. doi: 10.4022/jafib.894

37. Patel N, Ibrahim S, Shah J, et al. Deglutition syncope. Proc (Bayl Univ Med Cent) 2017; 30(3): 293-294. doi: 10.1080/08998280.2017.11929619

38. Kounis NG, Zavras GM, Kitrou MP, et al. Unusual electrocardiographic manifestations in conditions with increased intrathoracic pressure. Acta Cardiol. 1988; 43(6): 653-661.

39. Maruyama T, Fukata M, Akashi K. Association of atrial fibrillation and gastroesophageal reflux disease: Natural and therapeutic linkage of the two common diseases. J Arrhythm. 2018; 35(1): 43-51. doi:10.1002/ joa3.12125

40. Singh M, Sood A, Rehman MU, et al. Elevated Hemi-diaphragms as a Cause of ST-segment Elevation: A case report and review of literature. J Electrocardiol. 2017; 50(5): 681-685. doi: 10.1016/j. jelectrocard.2017.04.001

41. Khouzam RN, Akhtar A, Minderman D, et al. Echocardiographic aspects of hiatal hernia: A review. J Clin Ultrasound. 2007; 35(4): 196-203. doi: 10.1002/jcu.20312

42. Yang SS, Wagner P, Dennis C. Images in cardiovascular medicine. Hiatal hernia masquerading as left atrial mass. Circulation. 1996; 93(4): 836. doi: 10.1161/01.cir.93.4.836

43. Oishi Y, Ishimoto T, Nagase N, et al. Syncope upon swallowing caused by an esophageal hiatal hernia compressing the left atrium: a case report. Echocardiography 2004; 21(1): 61-64. doi: 10.1111/j.07422822.2004.03005.x

44. Lim HS, Leong DP, Alasady M. Massive hiatus hernia mimicking a left atrial mass. Heart Lung Circ. 2013; 22(10): 875-876. doi: 10.1016/j. hlc.2013.01.001

45. Koskinas KC, Oikonomou K, Karapatsoudi E, et al. Echocardiographic manifestation of hiatus hernia simulating a left atrial mass: case report. Cardiovasc Ultrasound. 2008; 6: 46. doi: 10.1186/1476-7120-6-46

46. Innasimuthu AL, Rao GK, Chuah S. Left atrial compression by a hiatus hernia. J Cardiovasc Comput Tomogr. 2007; 1(2): 106-107. doi: 10.1016/j. ject.2007.04.010

47. Brown A, Austin D, Kanakala V. Cardiac compression due to gastric volvulus: an unusual cause of chest pain. BMJ Case Rep. 2017. doi:10.1136/bcr-2017-219595

48. Kim SH, Kim MG, Kim SJ, et al. Unusual Diaphragmatic Hernias Mimicking Cardiac Masses. J Cardiovasc Ultrasound. 2015; 23(2): 107-112. doi: 10.4250/jcu.2015.23.2.107

49. Matar A, Mroue J, Camporesi E, et al. Large Hiatal Hernia Compressing the Heart. Am J Cardiol. 2016; 117(3): 483-484.

50. Gupta M, Nanda NC, Inamdar V. Two- and three-dimensional transthoracic echocardiographic assessment of hiatal hernia. Echocardiography. 2008; 25(7): 790-793. doi: 10.1111/j.15408175.2008.00702.x

51. Torres D, Parrinello G, Cardillo M, et al. Large hiatal hernia at chest radiography in a woman with cardiorespiratory symptoms. Am J Emerg Med. 2012; 30(9): 2103.e1-2103.e21033. doi: 10.1016/j.ajem.2012.03.009

52. Palios J, Clements S.Jr, Lerakis S. Chest pain due to hiatal hernia mimicking as cardiac mass. Acute Card Care. 2014; 16(2): 88-89. doi: $10.3109 / 17482941.2014 .889313$

53. Langberg S, Favot M. Hiatal Hernia Mimicking Aortic Aneurysm on Point-of-care Echocardiography. Clin Pract Cases Emerg Med. 2017; 1(4): 419-420. doi: 10.5811/cpcem.2017.6.33450

54. Sonsöz MR, Gören MT, Buğra Z. A suspicious left atrial mass in a patient with stroke: Hiatal hernia. Anatol J Cardiol. 2019; 22(2): 5002. doi: 10.14744/AnatolJCardiol.2019.62678

55. D'Cruz IA, Hancock HL. Echocardiographic characteristics of diaphragmatic hiatus hernia. Am J Cardiol. 1995; 75(4): 308-310. doi: 10.1016/0002-9149(95)80049-x 
56. Smelley M, Lang RM. Large mass impinging on the left atrium: diagnostic value of a new cocktail. J Am Soc Echocardiogr. 2007; 20(12). doi: 10.1016/j.echo.2007.05.010

57. Bowles MH, Lipman RE. Hiatal hernia: the "X" factor in transesophageal echocardiography. J Am Soc Echocardiogr. 1993; 6(6): 631-633. doi: 10.1016/s0894-7317(14)80184-3

58. Frans EE, Nanda NC, Patel V, et al. Transesophageal two-dimensional echocardiographic identification of hiatal hernia. Echocardiography. 2005; 22(6): 533-535. doi:10.1111/j.1540-8175.2005.50017.x

59. Siu CW, Jim MH, Ho HH, et al. Recurrent acute heart failure caused by sliding hiatus hernia. Postgrad Med J. 2005; 81(954): 268-269. doi: 10.1136/pgmj.2004.023416

60. Ishibashi Y, Nishigami K, Watanabe M, et al. Heart failure induced by the restrictive left ventricle due to hiatus hernia. J Echocardiogr. 2013; 11(3): 103-105. doi: 10.1007/s12574-013-0177-x

61. Matsuda M, Okutani R, Ueda M, et al. A large hiatal hernia exacerbated after aortic surgery: an unusual cause of heart failure. J Cardiothorac Vasc Anesth. 2012; 26(4): 41-42. doi: 10.1053/j.jvca.2012.02.011

62. Kawabe K, Tsutsumi N, Ikejiri K. Pseudo-heart Failure Due to a Large Hiatal Hernia. Intern Med. 2019; 58(23): 3483-3484. doi: 10.2169/ internalmedicine.3167-19

63. Malik SB, Chen N, Parker RA, et al. Transthoracic Echocardiography: Pitfalls and Limitations as Delineated at Cardiac CT and MR Imaging. 2017; 37(2): 383-406. doi: 10.1148/rg.2017160105
64. Devbhandari MP, Khan MA, Hooper TL. Cardiac compression following cardiac surgery due to unrecognised hiatus hernia. Eur J Cardiothorac Surg. 2007; 32(5): 813-815. doi: 10.1016/j.ejcts.2007.08.002 65. Papoulidis P, Beatty JW, Dandekar U. Hiatal hernia causing extrapericardial tamponade after coronary bypass surgery. Interact Cardiovasc Thorac Surg. 2014; 19(4): 716-717. doi: 10.1093/icvts/ivu215

66. Sobczyk D, Darocha T, Gałazkowski R, et al. Echocardiography Is Essential in Detection of Cardiac Tamponade Due to Sliding Hiatal Hernia. J Cardiothorac Vasc Anesth. 2015; 29(5): 60-61. doi: 10.1053/j. jvca.2015.04.008

67. Saito H, Miyazaki T, Sohda M, et al. Postprandial cardiogenic syncope caused by gastric polyp-induced pyloric obstruction in an elderly woman with a giant hiatal hernia: a case report. Surg Case Rep. 2017; 3(1): 124. doi: 10.1186/s40792-017-0403-2

68. Vanerio G. Syncope caused by huge hiatal hernia. Case Rep Cardiol. 2011; 560734. doi: 10.1155/2011/560734

69. Coolidge AM, Czerniach D, Wiener DC. Intestinal Tamponade. Ann Thorac Surg. 2019; 108(3): 193-194. doi: 10.1016/j.athoracsur.2019.01.048 70. Oishi Y, Ishimoto T, Nagase N, et al. Syncope upon swallowing caused by an esophageal hiatal hernia compressing the left atrium: a case report. Echocardiography. 2004; 21(1): 61-64. doi: 10.1111/j.07422822.2004.03005.x

71. Maekawa T, Suematsu M, Shimada T, et al. Unusual swallow syncope caused by huge hiatal hernia. Intern Med. 2002; 41(3): 199-201. doi: 10.2169/internalmedicine.41.199 